\title{
Comparative Mechanical Properties of Bulk-Fill Resins
}

\author{
Atabek Didem, Yalçın Gözde, Öztaş Nurhan \\ Department of Pedodontics, Faculty of Dentistry, Gazi University, Ankara, Turkey \\ Email: dtdidem@hotmail.com, gozdeyalcın@hotmail.com, nurhanoz@gazi.edu.tr
}

Received 4 March 2014; revised 3 April 2014; accepted 13 April 2014

Copyright (C) 2014 by authors and Scientific Research Publishing Inc.

This work is licensed under the Creative Commons Attribution International License (CC BY). http://creativecommons.org/licenses/by/4.0/

(c) (i) Open Access

\begin{abstract}
Aim: The aim of this study was to compare the flexural and compressive strengths of a new sonicactivated bulk-fill system (Sonicfill) with other bulk-fill resins and a universal posterior composite resin. Materials and Methods: A low-stress flowable base resin material (SDR), a bulk-fill composite resin (Tetric Evo Ceram), a universal posterior composite (GC G-aenial), and the Sonicfill system were compared. The specimens were prepared for each group following ISO Standard 4049 (flexural strength) and ADA 27 specifications (compressive strength). One-way variance analysis and Kruskal-Wallis tests were used to determine the statistical differences among groups $(p<0.05)$. Results: The Sonicfill system presented significantly higher compressive strength than other groups $(p<0.001)$. For flexural strength results, although the Sonicfill system showed the highest values, no statistically significant differences were determined among all groups $(p>$ 0.001). Conclusion: Due to the ability to place restorations with single increment and ease of use, the Sonicfill system can be an alternative for posterior restorations.
\end{abstract}

\section{Keywords}

Bulk-Fill, Composite Resin, Dental Materials

\section{Introduction}

The introduction of flowable composites provides expanded options for restorative dentistry. Flowable composites are low-viscosity resin composites obtained from formulations with $20 \%-25 \%$ lower filler loading and increased resin content than conventional resins. The reduced viscosity of the mixture makes their placement possible by injection syringes and limits stickiness. Although the first-generation flowable composites were used only as liners due to low elastic modulus, second-generation flowables are developed for use in bulk restorations and as liner in class I and II restorations [1]-[5]. According to the manufacturer's data, Surefill SDR (Dentsply, 
Konstanz, Germany) was marketed as a low-stress flowable base material that can be placed in layers up to 4 $\mathrm{mm}$ in thickness without negatively affecting polymerization shrinkage, cavity adaptation or degree of conversion [3]. Also, Tetric EvoCeram Bulk-fill (Ivoclar Vivadent AG, Liechtenstein) was introduced to the market as a bulk-fill restorative material with the ability to place the restoration with a single increment (up to $4 \mathrm{~mm}$ ) [4].

Nowadays a new sonic-activated bulk-fill system (Sonicfill, Kerr Corp, USA/KaVo, Germany) was introduced to the market for posterior bulk restorations. According to the manufacturer's data, the Sonicfill system is a unique, sonic-activated bulk-fill system comprised of a specially designed hand piece and a new composite material in unidose tips. The composite is a combination of flowable and universal composites and incorporates a highly-filled proprietary resin with special modifiers that react to sonic energy. As sonic energy is applied to the hand piece with five different levels of flowability, the modifier causes the viscosity to drop (up to 87\%), increasing the flowability of the composite. When the sonic energy is stopped, the composite returns to a more viscous, non-slumping state for carving and contouring. In addition, the manufacturer informs that increased levels of photoinitiators in the composite material allow a full $5 \mathrm{~mm}$ depth of cure in 20 seconds with a 550 $\mathrm{mW} / \mathrm{cm}^{2}$ light source [6].

Although the flowable bulk restorations present some advantages for dentists, the number of studies which have evaluated their properties is still limited [3]-[5]. Research studies on the materials' physical properties are clinically relevant. In fact, these kinds of studies are of paramount importance when the material is to be applied in stress-bearing and clinical uses. The flexural or bending strength is a measure of the fracture resistance of a material [7]. The compressive strength has an important role in the mastication process [8] [9]. In the literature there is very few knowledge about the mechanical properties of new-generation bulk restoration materials. In addition, the Sonicfill system is the newest material in this area. The aim of this study was to investigate the flexural and compressive strengths of Sonicfill system and compare the results with other bulk-fill materials (Surefill SDR, TetricEvoCeram Bulkfill) and a universal posterior composite resin (G-aenial Posterior, GC, Japan).

\section{Materials and Methods}

The materials used in this study are listed in Table 1.

\subsection{Flexural Strength}

Ten samples of each material were prepared by the same investigator according to International Standards Organization (ISO) 4049 specifications $(25 \times 2 \times 2 \mathrm{~mm})$ by using stainless steel split molds and light cured for $20 \mathrm{~s}$ by using a blue light-emitting diode with a $550 \mathrm{~mW} / \mathrm{cm}^{2}$ light source (Hilux Ledmax 550, Benlioğlu Dental, Ankara, Turkey) according to the manufacturer's directions. After polymerization, samples were stored in distilled water at $37^{\circ} \mathrm{C}$ for 24 hours. The flexural tests were performed with a Universal Testing Machine (LF Plus, LLOYD, Instrument, AmetekInc, England) at a cross-head speed of 1mm/min, with $2 \mathrm{Kn}$ loading force.

\subsection{Compressive Strength}

Ten cylindrical samples of each material were prepared by the same investigator according to American Dental Association (ADA) 27 specifications ( $3 \mathrm{~mm}$ diameter $\times 6 \mathrm{~mm}$ height) by using stainless steel split molds and light cured for $20 \mathrm{~s}$ by using a blue light-emitting diode with a $550 \mathrm{~mW} / \mathrm{cm}^{2}$ light source (Hilux Ledmax 550). The universal posterior composite samples were prepared incrementally. The other materials were prepared according to the to the manufacturer's directions for cavities deeper than $4 / 5 \mathrm{~mm}$ height. Samples for compressive

Table 1. The materials used the study.

\begin{tabular}{ccc} 
Material Catagory & Brand Name & Manufacturer \\
\hline Nanohybrid Composite & Sonic Fill ${ }^{\mathrm{TM}}$ & Kerr Corp. USA/KAVO. Germany \\
Nanohybrid Composite & TetricEvoCeram Bulk Fill & Ivoclar. Vivadent. AG. Liechtenstein \\
Flowable Composite & SureFil $^{\circledR}$ SDR $^{\circledR}$ Flow & Dentsply. Konstanz. Germany \\
Universal Composite & G-aenial Posterior & GC Corp. Tokyo. Japan \\
\hline
\end{tabular}


strength tests were stored in distilled water at $37^{\circ} \mathrm{C}$ for 24 hours. The compressive tests were performed with a Universal Testing Machine (LF Plus, LLOYD, Instrument, Ametek Inc, England) at a cross-head speed for 0.05 $\mathrm{mm} / \mathrm{min}$.

Compressive strength and flexural strength tests data's were subjected to one-way variance analysis and Kruskal-Wallis tests at a significance level of 0.05 .

\section{Results}

The mean flexural and compressive strength values (MPa), standard deviations, and statistical results of the materials are given in Table 2 and Figure 1.

Compressive strength values for the Sonicfill system (316.596 \pm 22.23$)$ and universal posterior composite resin G-aenial (287.9498 \pm 28.12$)$ were significantly greater than SDR (218.6399 \pm 18.79$)$ and Tetric EvoCeram (203.6807 \pm 26.53$)(p<0.001)$. No significant difference was observed between the Sonicfill system and universal posterior composite resin $(p=0.061)$. No significant difference was observed between SDR and Tetric EvoCeram $(p=0.518)$.

Although the greatest flexural strength values were observed for the Sonicfill system (163.47 \pm 49.74$)$, no statistically significant differences were observed among all groups (G-aenial: $158.12 \pm 11.92$ SDR: $142.04 \pm$ 27.89, Tetric EvoCeram: $135.16 \pm 31.16)(p>0.001)$.

\section{Discussion}

Direct posterior restorations play a significant role in dentistry. But achieving predictable and successful outcomes remains a main concern for practitioners, due to technique sensitivity and the numerous steps required for proper placement. In addition, several negative effects in resin-based composite restorations are frequently connected to polymerization shrinkage stress [3] [10]. Filling all of a tooth preparation with a composite at one time

Table 2. Mean compressive and flexural strength values of the materials tested.

\begin{tabular}{cccccc}
\hline Groups & \multicolumn{2}{c}{ Compressive Strength } & \multicolumn{2}{c}{ Flexural Strength } \\
\hline & $\mathbf{N}$ & Mean (MPa) & Std. Dev. & Mean (MPa) & Std. Dev. \\
\hline Sonicfill System & 10 & $316.1596^{\mathrm{a}}$ & 22.23 & 163.47 & 49.74 \\
SDR & 10 & $218.6399^{\mathrm{b}}$ & 18.79 & 142.04 & 27.89 \\
Tetric EvoCeram & 10 & $203.6807^{\mathrm{b}}$ & 26.53 & 135.16 & 31.16 \\
G-aenial & 10 & $287.9498^{\mathrm{a}}$ & 28.12 & 158.12 & 11.92 \\
\hline
\end{tabular}

Same lower cases in the same column mean no statistically significant difference $(p<0.001)$.

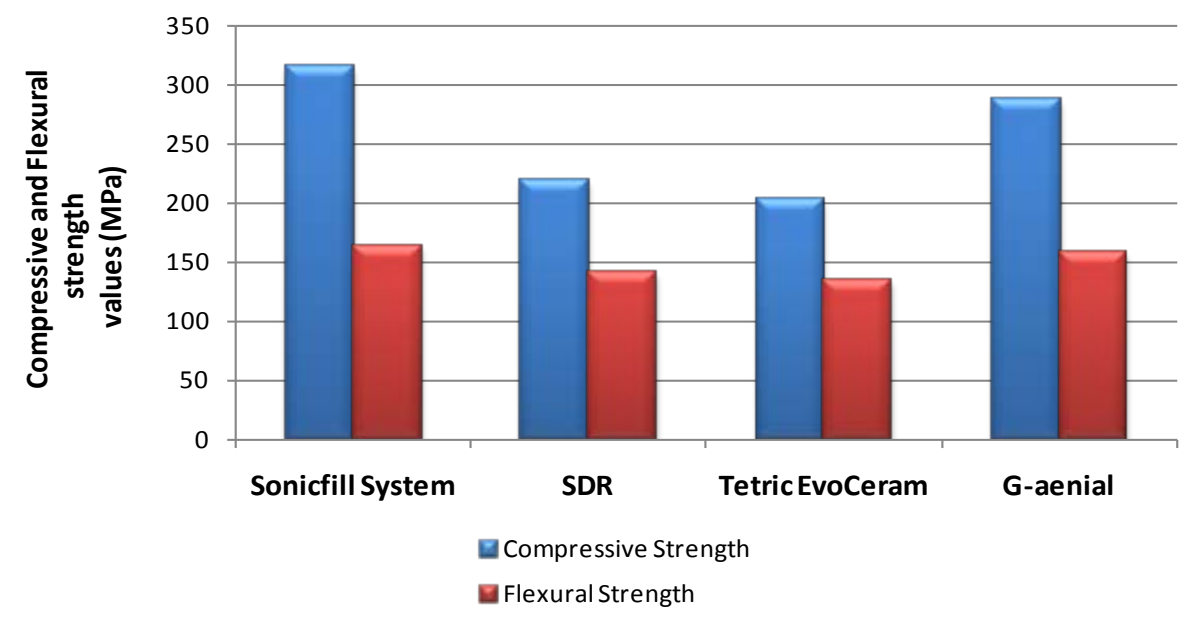

Figure 1. Comparison of the compressive and flexural strength values of the materials tested. 
has obvious advantages for both patients and practitioners [11].

Although a new category of bulk-fill resin-based composites have been introduced, there are very few studies investigating the clinical and laboratory success of these materials [1] [4] [12]-[14]. The manufacturers claimed that bulk-fill materials can achieve a depth of cure of $6 \mathrm{~mm}$. In this context, the studies were focused on the polymerization shrinkage [13], depth of cure [14], marginal quality [4], shrinkage stress [3], and surface morphology [1], especially of SDR. In one study the flexural strength of SDR was investigated [14]. The Sonicfill system is a new development in this area and in the limitation of our knowledge this is the first study in which the main physical properties of either the Sonicfill system or new bulk-fill materials were investigated. This study compared the compressive and flexural strengths of three resin based composites that, according to their manufacturers, are capable of being placed in bulk.

The performance of biomaterials is most often evaluated using laboratory tests. Restorative materials and teeth are generally subjected to both compressive and flexural forces, so flexural and compressive strength tests are very important to test and determine the mechanical properties of materials [8] [9]. The compressive strength has an important role in the mastication process since several of the masticatory forces are of a compressive nature [8]. In addition, a material's fracture-related properties are usually determined by flexural strength testing and are especially important if the material is used for Class I, II, or IV cavities, which are usually subjected to high forces [15]. For screening of resin-based materials, the flexural strength test is one of the mechanical properties selected by ISO [16]. Similarly, the ADA established guidelines for in-vitro tests of resin-based materials [7]. In this study, the specimen dimensions were prepared according to ISO 4049 specifications for a flexural strength test and ADA 27 specifications for a compressive strength test.

In the study, a low-stress flowable base material (SDR that can be placed in layers up to $4 \mathrm{~mm}$ ), a bulk-fill composite resin (Tetric Evo Ceram), a universal posterior composite (G-aenial), and the Sonicfill system were compared. The ISO has set $80 \mathrm{MPa}$ as the minimum flexural strength for polymer-based filling and restorative materials claimed suitable and acceptable for restorations involving outer occlusal surfaces [17]. Accordingly, our results showed that all of the tested materials can be used in occlusal areas. Although no statistically significant differences were observed among all groups, the greatest flexural strength values were observed for the Sonicfill system. Additionally, the present study demonstrated that compressive strength values for the Sonicfill system and G-aenial were significantly greater than SDR and Tetric EvoCeram.

It is generally assumed that the higher the filler loading, the higher the composite mechanical properties [1]. It is known that the average filler content's of flowables vary from $45 \%$ to $65 \%$ by weight. In this context, the Sonicfill system, with highest flexural and compressive strength values (163.47 MPa, 316.15 MPa, respectively), is also the material with the greatest filler loading (83.5\%), as seen in Table 1. Similarly, Tetric Evo Ceram and SDR, which present the lowest strength values for both flexural and compressive tests, also have the minimum amount of filler loadings ( $79 \%$ - $81 \%$, and $68 \%$, respectively).

These results can also be explained by the working principle of the Sonicfill system. The composite used in this system is a combination of flowable and universal composites and incorporates a highly-filled proprietary resin with special modifiers that react to sonic energy. As sonic energy is applied through the hand piece, the modifier causes the viscosity to drop (up to 87\%), increasing the flowability of the composite. When the sonic energy is stopped, the composite returns to a more viscous, non-slumping state [6]. In this context, the Sonicfill system cannot be classified as a flowable composite. The flowability is adjusted by the practitioner through the hand piece with five levels of flowability and when the sonic activation stopped, the material becomes similar to a universal composite structure. However, these tests need further clinical observations because occlusal forces may influence flexural and compressive strengths.

Physical property studies are accepted methods to evaluate resin materials. The present study showed that all of the tested materials are suitable and acceptable for restorations involving outer occlusal surfaces. The Sonicfill system created the greatest mechanical properties. Moreover, the bulk-fill technology has obvious advantages: 1) fewer voids may be present in the mass of the material, since all of it is placed at one time; 2) the technique would be faster than placing numerous increments if curing times were identical; 3) It may be easier than numerous increments [11] [14]. On the other hand, there are many questions in the minds of dentists about bulkfill technology because there are very few published data. Therefore, the clinical success will only be discovered after long periods of use by general practitioners. Further studies evaluating the long-term clinical success of bulk-fill resin based composites are needed. 


\section{Conclusion}

It can be concluded that the physical properties of the Sonicfill system demonstrated results for flexural strength tests comparable to universal composite, whereas the compressive strength tests revealed superior results to the other bulk-fill materials. Due to the ability to place restorations with a single increment (up to $5 \mathrm{~mm}$ ) and ease of use, by further in-vitro and in-vivo studies, the Sonicfill system may be an alternative for posterior restorations.

\section{References}

[1] Salerno, M., Derchi, G., Thorat, S., Ceseracciu, L., Ruffilli, R. and Barone, A.C. (2011) Surface Morphology and Mechanical Properties of New-Generation Flowable Resin Composites for Dental Restoration. Dental Materials, 27, 1221-1228. http://dx.doi.org/10.1016/j.dental.2011.08.596

[2] Ozel, E., Korkmaz, Y., Attar, N. and Karabulut, E. (2008) Effect of One-Step Polishing Systems on Surface Roughness of Different Flowable Restorative Materials. Dental Materials Journal, 27, 755-764. http://dx.doi.org/10.4012/dmj.27.755

[3] Ilie, N. and Hickel, R. (2011) Investigations on a Methacrylate-Based Flowable Composite Based on the SDR ${ }^{\mathrm{TM}}$ Technology. Dental Materials, 27, 348-355. http://dx.doi.org/10.1016/j.dental.2010.11.014

[4] Roggendorf, M.J., Krämer, N., Appelt, A., Naumann, M. and Frankenberger, R. (2011) Marginal Quality of Flowable 4-mm Base vs. Conventionally Layered Resin Composite. Journal of Dentistry, 39, 643-647. http://dx.doi.org/10.1016/j.jdent.2011.07.004

[5] Boaro, L.C., Gonçalves, F., Guimarães, T.C., Ferracane, J.L., Versluis, A. and Braga, R.R. (2010) Polymerization Stress, Shrinkage and Elastic Modulus of Current Low-Shrinkage Restorative Composites. Dental Materails, 26, 1144-1150. http://dx.doi.org/10.1016/j.dental.2010.08.003

[6] www.sonicfill.kerrdental.com

[7] Heintze, S.D. and Zimmerli, B. (2011) Relevance of in Vitro Tests of Adhesive and Composite Dental Materials. A Review in 3 Parts. Part 3: In Vitro Tests of Adhesive Systems. Schweiz Monatsschr Zahnmed, 121, 1024-1040.

[8] Silva, C.M. and Dias, K.R. (2009) Compressive Strength of Esthetic Restorative Materials Polymerized with QuartzTungsten-Halogen Light and Blue LED. Brazillian Dental Journal, 20, 54-57. http://dx.doi.org/10.1590/S0103-64402009000100009

[9] Gömeç, Y., Dörter, C., Dabanoglu, A. and Koray, F. (2005) Effect of Resin-Based Material Combination on the Compressive and the Flexural Strength. Journal of Oral Rehabilitation, 32, 122-127. http://dx.doi.org/10.1111/j.1365-2842.2004.01394.x

[10] Uçtaşli, M.B., Bala, O. and Güllü, A.V. (2004) Surface Roughness of Flowable and Packable Composite Resin Materials after Finishing with Abrasive Discs. Journal of Oral Rehabilitation, 31, 1197-1202. http://dx.doi.org/10.1111/j.1365-2842.2004.01341.x

[11] Christensen, G.J. (2012) Advantages and Challenges of Bulk-Fill Resins. Clinicians Report, 5, 1-5.

[12] Ilie, N. and Hickel, R. (2009) Investigations on Mechanical Behaviour of Dental Composites.Clinical Oral Investigations, 13, 427-438. http://dx.doi.org/10.1007/s00784-009-0258-4

[13] Burgess, J. and Cakir, D. (2010) Comparative Properties of Low-Shrinkage Composite Resins. Compendium of Continuing Education in Dentistry, 31, 10-15.

[14] Czasch, P. and Ilie, N. (2012) In Vitro Comparison of Mechanical Properties and Degree of Cure of Bulk Fill Composites. Clinical Oral Investigations, 17, 227-235.

[15] Ersoy, M., Civelek, A., L’Hotelier, E., Say, E.C. and Soyman, M. (2004) Physical Properties of Different Composites. Dental Materials Journal, 23, 278-283. http://dx.doi.org/10.4012/dmj.23.278

[16] International Standard ISO 4049 (2000) Polymer-Based Filling, Restorative and Luting Materials. Technical Committee 106-Dentistry. International Standards Organization, Geneva.

[17] Attar, N., Tam, L.E. and McComb, D. (2003) Flow, Strength, Stiffness and Radiopacity of Flowable Resin Composites. Journal of Canadian Dental Associations, 69, 516-521. 